Author Posting. (c) Taylor \& Francis, 2009.

This is the author's version of the work. It is posted here by permission of Taylor \& Francis for personal use, not for redistribution.

The definitive version was published in Language Awareness, Volume 18 Issue 3, August 2009.

doi : $10.1080 / 09658410903197264$

(http://dx.doi.org/10.1080/09658410903197264 )

\title{
Engagement with Language: Interrogating a construct
}

\section{Introduction}

In a recent review paper of Language Awareness (LA) I stated that despite being a very 'broad church', LA is given coherence in both classroom practice and research by its focus on engagement with language:

A shared concern, I would argue, of LA practitioners and researchers, is the notion of engagement with language. As collectively constructed over the last 15-20 years, LA does not refer to a purely intellectual awareness and is not passive. In the work discussed above, LA both engenders engagement with language and is constructed through it. ...The engagement can be intellectual, affective, social or political or, usually, a combination. Researchers are concerned much less with memorized or encyclopaedic knowledge than with LA as it encourages, facilitates, discourages or hinders particular types of engagement with language, be it by language learners, gatekeepers, the general public or other groups. (... 2007, p.302)

The problems with such a statement are all too obvious. What does engagement with language mean? Do we really need another term? Is it a useful concept, or just a fairly empty and ambiguous buzz word? The present paper is an attempt to answer these questions.

The everyday contexts in which the term 'engagement' is used are suggestive: cogs engage, armies engage in battle, people get engaged (to be married). It seems to suggest physical or metaphorical close contact, and some force driving things forward or pushing in a direction. It is an attractive metaphor, and a popular one in the literature on education (pupil engagement; literacy engagement) and in other areas such as management (work place engagement). Its meaning is, however, usually assumed rather than defined raising the possibility that one writer might not mean the same as another.

My own interest in engagement was triggered by a number of recent publications on learner variables such as motivation and learning strategies (e.g. Dornyei, 2006; Pavicic Takac, 2008) and a similar trend in postgraduate research proposals. Research into motivation attempts to understand what drives engagement, and studies of learning strategies deal with certain forms of engagement; how they can be encouraged and what their effect might be on learning. I would argue, therefore, that researchers and practitioners alike are currently trying to come to grips with 'engagement' as the place where learning happens.

In the field of LA, the term 'engagement' is often not defined. Some linguists to whom 'engagement' is central, use the term in its everyday sense. For example, Hyland (2003) and Batstone (2002) investigate learner engagement, and Borg (2007) looks at 
teachers' research engagement. But the term has recently been used by Storch (2008) specifically to denote instances of noticing as evidenced in language related episodes (LREs). Drawing in particular on Leow (1997) and Kuiken and Vedder (2002) who refer to 'simple and elaborate noticing' (and also 'perfunctory' and 'substantive' noticing, Qi and Lapkin, 2001) she distinguishes between two levels of engagement, limited and elaborate. The term 'engagement with language' is thus used by Storch to "describe the quality of the learners' metatalk" $(2008$, p. 99) and is linked to the quality of attention on which, as Storch (2008) points out, little research has been done.

It seems an intuitively apt term for what happens in LREs but is potentially a richer notion than this might imply. As a construct, the notion of engagement could provide ways of explaining why some linguistic or language related behaviours and attitudes seem to facilitate language learning and learning about language/s more than others. I would argue that in addition to its cognitive aspects it crucially involves a range of social and affective phenomena and that it is this complexity which justifies the construct.

In order to facilitate a clearer understanding, and make it researchable and able to be evaluated as a construct, 'engagement with language' needs detailed interrogation. The elements of the construct need to be laid bare, and that is what I will attempt to do below. The approach has two strands. First a methodology employed by Ellis (2004) to interrogate another notion, 'L2 explicit knowledge' is explained and then applied. The figure below is my summary of the steps he follows.

For the purposes of this paper, $\mathrm{X}$ in figure 1 is 'engagement with language'. The first part of the analysis and discussion will follow Ellis's methodology as far as the expanded definition. Having reached a more in depth understanding of the construct, the paper continues with a brief discussion of the relationship between engagement and LA. 


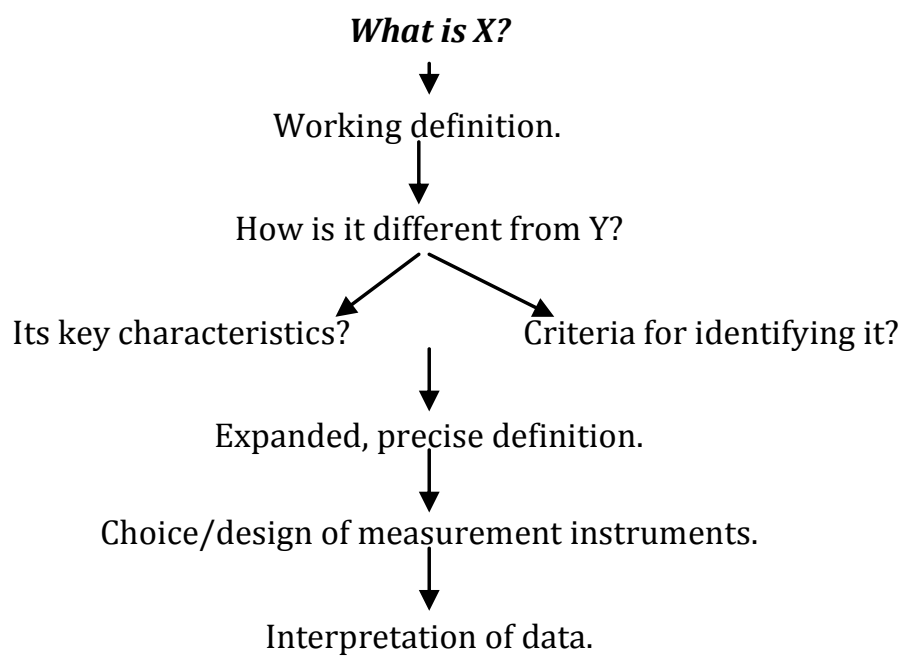

Figure 1 Methodology for interrogating and developing a construct (Based on Ellis, 2004)

In the second part of the paper the various components of the construct will be applied to some interview and observation data. This is for illustration only as the data was originally collected for a different purpose. ESOL teachers and their adult students were interviewed and observed in class (... 2005). For the present paper, an analysis of 'engagement with language' was carried out on one set of field notes from the classroom observations and one of the interview sessions, with two ESOL students. The analysis leads to suggestions of factors which might encourage or discourage engagement with language. The paper concludes with an evaluation of the construct and suggestions for ways ahead.

\section{What is 'Engagement with Language'?}

The working definition from which this investigation starts is as follows:

\section{Working definition of Engagement with Language}

In the context of language learning and use,

'Engagement with Language' (Engagement) is a cognitive, and/or affective and/or social state and process in which the learner is the agent and language is object, and may be vehicle (means of communication).

For convenience, I will from time to time refer to 'engagement with language' as Engagement, and capital E will be used also on the verb ('Engage' rather than 'engage with language').

In the definition, I distinguish between when the language is the object of Engagement and when it is a vehicle of communication. The term 'object'has been preferred to other possibilities such as 'form' or 'system' to signal the inclusion of social and other non-grammar aspects of language. Likewise, 'vehicle' has been chosen in preference to, for example, 'use' as it seems to carry fewer limiting connotations. In the definition, language being the object is seen as primary, while language as vehicle is a 
secondary and therefore not necessary feature of engagement. The reasons should become clear in the following discussion.

An example of 'language as object' in the classroom would be learners doing language exercises or tasks, perhaps discussing solutions in the L1 or target language (and thus giving rise to the much studied language related episodes, or LREs). Collaborative dialogue (Swain, 2000) or what Swain has later referred to as 'languaging' (Swain, 2006) is thus one manifestation of Engagement. A classroom example of language as vehicle would be learners doing a communicative task in the target language without paying attention to aspects other than communicative efficiency. In many contexts the two aspects of Engagement will both be present. I would argue, however, that language can also be used without Engagement. Somebody speaking/writing spontaneously and automatically for purely communicative ends may be socially engaged, but not Engaged with Language. It cannot be assumed therefore that use of language is in and by itself evidence of Engagement in the sense discussed here. Also, Engagement is gradable, i.e. one can be more or less Engaged, and it would seem to possess a number of qualities.

These are implied by the working definition, in the statement that Engagement involves particular cognitive states, and/or affective orientations and/or social attitudes, as well as actions and behaviours. In other words, that it should be analyzed as both a state and a process. The cognitive, affective and social aspects of Engagement overlap, and are likely to affect each other, but the separation is made to allow a more in depth analysis below.

\section{How is engagement different from similar notions?}

Three notions which seem semantically close to Engagement are 'involvement', 'commitment' and 'motivation'. In the table below, I have attempted to establish to what extent and in what way Engagement differs or is similar to its semantic neighbours ${ }^{1}$.

Table 1 The relationship of engagement to neighbouring constructs.

\begin{tabular}{l|c|c|c|c} 
Components Constructs & Engagement & Involvement & Commitment & Motivation \\
\hline Cognitive & & & & \\
\hline Alertness & $\bullet$ & $\bullet$ & & \\
\hline Focused attention & $\bullet$ & & & \\
\hline $\begin{array}{l}\text { Action knowledge (making } \\
\text { knowledge one's own) }\end{array}$ & $\bullet$ & & & \\
\hline & & & & \\
\hline Affective & & & $\bullet$ & $\bullet$ \\
\hline Positive attitude to object & $\bullet$ & & $\bullet$ & $\bullet$ \\
\hline Purposeful & $\bullet$ & & & $\bullet$ \\
\hline Willingness/choice & $\bullet$ & & & \\
\hline Autonomy & $\bullet$ & & & \\
\hline & & & & \\
\hline Social & $\bullet$ & $\bullet$ & & \\
\hline Interaction/doing & $\bullet$ & & & \\
\hline Agency & & & & $\bullet$
\end{tabular}


The table represents an attempt to unpack the meanings of 'engagement' and terms semantically close to it, as they are commonly used. Along the horizontal top row, I have chosen to compare it with terms which are common currency, like 'involvement', rather than less common notions such as 'investment' (Norton, 1995) on which there may be less intuitive agreement (but see comments below). The shaded boxes containing a dot $(\bullet)$ each mark a feature implied by the term at the top of the column. For example, the table makes the claim that the terms 'engagement' and 'involvement' both imply some level of alertness on the part of the engaged or involved individual. It does not claim that committed or motivated individuals cannot be alert, only that the terms 'commitment' and 'motivation' do not imply anything about alertness.

The comparison with' involvement', in the table, implies also that while focused attention is necessary for engagement, involvement can be unfocused. Likewise, in this analysis only 'engagement' involves a process of taking personal ownership of knowledge, turning it into so called 'action knowledge' (Little, 2007, p. 19, discussing Barnes, 1976) on which further action can be based. It is posited that 'involvement' is not necessarily affective. The affective dimension is more obviously a component of 'commitment' and 'motivation', which are similar to 'engagement' in that they rely on a positive attitude and willingness, and are to some degree purposeful.

'Engagement' and 'motivation', according to my analysis, are similar in that both imply a degree of autonomy. Van Lier (2007, p.48) explains autonomy as 'the feeling of being the agent of one's own actions' while Little (2007, p.15, citing Holec, 1981) describes it as 'the ability to take charge of one's own learning'. I have assumed that autonomy is an affective disposition and that a motivated or engaged person is characterized by some degree of autonomy; but that this is not necessarily the case with a person who is merely involved.

The two features unique to 'engagement' in the table above are the cognitive features 'focused attention' and 'action knowledge' (making knowledge one's own). The picture emerging is of an individual who is actively constructing their knowledge not only by mental processes but equally by being socially active and taking initiatives. On this analysis, all the nine features marked in the table are implied by the term 'engagement'.

In table 2 below, the key characteristics, or qualities, of the more specific construct, Engagement (with Language), are identified. Following the working definition, it is analysed as comprising cognitive, and/or affective and/or social states and processes.

Table 2 Key Characteristics of Engagement with Language

\begin{tabular}{|c|c|c|c|}
\hline & Cognitive & Affective & Social \\
\hline $\begin{array}{l}\text { Key } \\
\text { Characteristics }\end{array}$ & $\begin{array}{l}\text { State: Heightened } \\
\text { alertness; focused } \\
\text { attention } \\
\text { Process: Focused } \\
\text { reflection and problem } \\
\text { solving }\end{array}$ & $\begin{array}{l}\text { State: Positive orientation } \\
\text { towards the language, the } \\
\text { interlocutor, and/or what } \\
\text { they represent } \\
\text { Process: Willingness to } \\
\text { interact with the language } \\
\text { and/or interlocutor is } \\
\text { maintained/heightened }\end{array}$ & $\begin{array}{l}\text { State: Behavioural } \\
\text { readiness to interact } \\
\text { Process: Initiating and } \\
\text { maintaining interaction.* }\end{array}$ \\
\hline
\end{tabular}

Note. *Maintenance may involve not only keeping interaction going but also caring for the quality of interaction. 
The characteristics are only meaningful if they can be operationalized - the "how can it be identified' step in the fig. 1 model. The following table is an attempt to indicate how it could be done. In the table below, L stands for 'learner' but would not necessarily be a learner in the formal sense. L could be any individual potentially engaging with language. The table suggests for each kind of Engagement some questions which could be asked in order to establish its degree and qualities. A person might, for example, be cognitively but not socially Engaged, or Engaged to different degrees in different spheres.

Table 3 Criteria for Identifying Engagement with Language

\begin{tabular}{|c|c|c|}
\hline Cognitive & Affective & Social \\
\hline $\begin{array}{l}\text { How alert? (Does L seem } \\
\text { energetic or lethargic? } \\
\text { Does L seem to notice } \\
\text { language/interaction } \\
\text { features?) } \\
\text { How focused? } \\
\text { (Does L's mind seem to } \\
\text { wander?) } \\
\text { How reflective?; } \\
\text { How critical/analytical? } \\
\text { (Does L compare? Does L } \\
\text { ask questions? Does L } \\
\text { infer/ draw conclusions?) }\end{array}$ & $\begin{array}{l}\text { How willing to engage? (Is } \\
\text { L withdrawn or eager to } \\
\text { participate?) } \\
\text { How purposeful? } \\
\text { (Does L seem to be 'going } \\
\text { somewhere' or just } \\
\text { coasting?) } \\
\text { How autonomous? } \\
\text { (Is L's behaviour } \\
\text { dependent or } \\
\text { independent?) }\end{array}$ & $\begin{array}{l}\text { How interactive } \\
\text { (Verbal and other } \\
\text { behaviours? Does L use } \\
\text { interaction for } \\
\text { learning?) } \\
\text { How supportive? } \\
\text { (Verbal and other } \\
\text { behaviours? Does L } \\
\text { engage in negotiation } \\
\text { and scaffolding? ) } \\
\text { Leader or follower? } \\
\text { (Are L's interactions } \\
\text { reactive or initiating?) }\end{array}$ \\
\hline
\end{tabular}

The posited characteristics of Engagement and their operationalization (Tables 2 and 3) may not be exhaustive, but they offer a principled and manageable framework for the interrogation and analysis of the level of engagement, and the identification of the characteristics of that engagement. They can be said to validate the earlier semantic unpacking and comparison (Table 1) to the extent that there are clear links between them. For example, Table 1 suggests that a cognitively Engaged person is alert, pays focused attention and constructs their own knowledge. Table 3 operationalizes that by asking questions around how alert, focused, reflective and critical/analytical the person is. Affective and social Engagement are operationalized in similar ways.

An expanded, more precise definition can now be attempted.

\section{Expanded definition of Engagement with Language}

In the context of language learning and use,

Engagement with Language (Engagement) is a cognitive, and/or affective, and/or social state and process in which the learner is the agent and language is object (and sometimes vehicle).

- Cognitively, the Engaged individual is alert, pays focused attention and constructs their own knowledge.

- Affectively, the Engaged individual has a positive, purposeful, willing and autonomous disposition towards the object (language, the language and/ or what it represents)

- Socially, the Engaged individual is interactive and initiating. 
The definition is not meant to be 'the last word' on the subject. Instead, it raises a number of questions and needs to be further refined by being debated and challenged. For example, in terms of determining when Engagement is or is not present, are some features of Engagement necessary while others are optional? For example, is Engagement always cognitive to some degree, but not necessarily affective and/or social? Is it possible to be socially Engaged without the presence of some interactivity? If Engagement is a matter of degree, how does one establish a minimum level of Engagement? I have assumed above that from a learning point of view, Engagement matters. If so, are all kinds of Engagement equally effective? One purpose of the above analysis, is to make such questions researchable. A final question, to which I will return below, is whether this specification of the construct can help establish factors which facilitate or hinder Engagement with Language.

\section{Engagement with Language and Language Awareness}

Having determined what Engagement means, and acknowledging that this is a work in progress, the purpose of the remainder of this paper is to try and determine how useful (or otherwise) the construct might be to LA, and where it might be taken in future LA research.

LA can be considered from two different angles in relation to Engagement: as the likely outcome of Engagement with Language, and as a resource which feeds Engagement. LA is most obviously the outcome of Engagement when language is the object. The degree to which language as vehicle contributes to LA may depend on the user's analytical skills and what other demands there are on their attentional resources. The figure below attempts to illustrate these relationships.

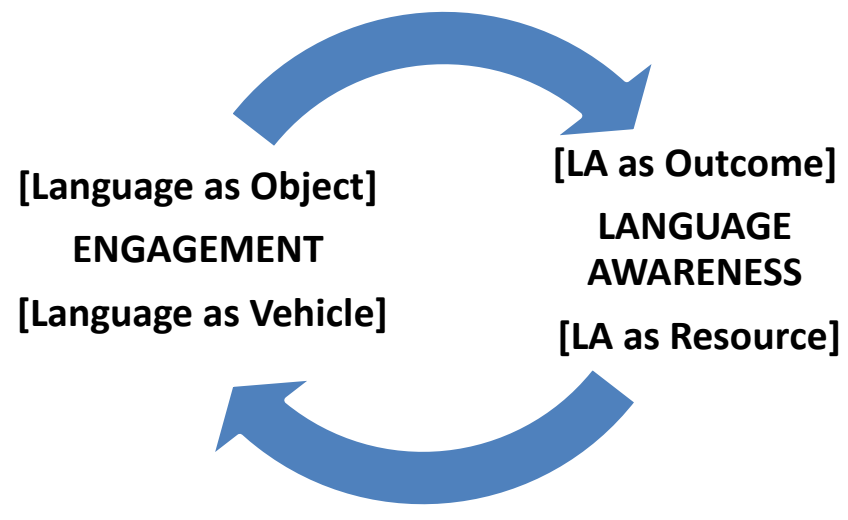

Figure 2 The Engagement with Language - Language Awareness Cycle

According to this figure, once some LA has been acquired it is a resource which can be drawn on when Engaging with Language, either as object and vehicle, or as object only. Such Engagement is likely to enhance or add to the person's LA, and thus to create a richer store of LA for further Engagement and knowledge creation. The model in fig.2 implies that LA research and practice are intimately and crucially concerned with the characteristics and qualities of Engagement with Language. A particularly interesting area of investigation might be how this cycle is affected by multilingualism (cf. Singleton and Aronin, 2007). The model would need to be tested in empirical (or experimental) 
research, but this is beyond the scope of the present paper. Below I will only try to illustrate with some sample data how the construct might help us understand some of what happens in language classrooms.

\section{Some ESOL learners' Engagement with Language}

The above criteria for identifying Engagement (Table 3) indicate the need for micro analysis of conversation data or audio/video recording of classroom interaction but for the purposes of this paper I have, as previously indicated, merely reanalyzed some already available data. Three adult ESOL student groups were observed by two researchers taking field notes, in 12 class sessions of about 50 minutes each. Subsequently, eight of the ESOL students and the four ESOL class teachers were interviewed. The focus of the observations was on how the teachers managed grammar instruction and on the learners' engagement. The interviews explored attitudes to the teaching methods and materials, and rationales for such perceptions. Below I will discuss some illustrative extracts from the observation field notes, and from a transcript of one 30 minute pair interview with ESOL students from the same class as in the observation extract ${ }^{2}$. I believe the data sheds some light on the role of Engagement in the creation and use of LA (LA as outcome and resource). The section concludes with suggestions for factors which might facilitate or hinder Engagement.

\section{Cognitive Engagement}

I have taken it as given that the development of LA, and the learning of a language/ languages, normally relies on a combination of cognitive, affective and social factors. Below I will attempt to be more specific by isolating instances of the three aspects of Engagement referred to above. While this separation is somewhat artificial (there are clearly strong interrelationships) I believe it can help provide a rich analysis.

In creating classroom conditions which are conducive to cognitive Engagement with Language, the teacher has a key role. In the sample observation the teacher kept her voice at a fairly low pitch and low volume. This could be calming and help students concentrate, though a livelier voice could help some stay alert. When she was monitoring students' work, the teacher often kneeled down to reach eye level with the seated students, as in the example extract below. Creating a degree of social intimacy in this way, might facilitate focused attention.

Extract 1 (Observation) - Creating the conditions for cognitive Engagement:

$\mathrm{S} 1$ and $\mathrm{S} 7$ discuss alternatives with $\mathrm{T}$ (newer/ more new) in private conference. $\mathrm{T}$ encourages $\mathrm{SS}$ to put the adjectives in sentences.

$\mathrm{T}$ reads some and laughs with SS. S tries out an example structure on the T. Discussion ensues one-to-one [T and S].

In the field notes, numbers were assigned to the students in the order they entered the classroom. In the extract, ' $\mathrm{T}$ ' is the teacher; ' $\mathrm{S}$ ' indicates a single student, 'SS' two or more students. Above, student 1 and student 7 were working together. In this episode the students had been given an exercise to do in pairs on using the comparative of adjectives. They were discussing which form of 'new' to use. The interaction was not tape recorded but parts of it could be overheard. 
These hushed discussions between a student or students and the teacher were quite frequent. The teacher rarely provided solutions but favoured guided discovery, which encouraged focused attention on the students' part, though this might have been for brief spells only. Also, it was difficult to tell whether in replying to the questions students drew inferences or relied on memory. The former would, presumably, require a higher degree of cognitive Engagement than the latter.

As adults come with an educational history, often including more than one language, it is not surprising that many have a fair degree of LA, including declarative grammar knowledge. This is evident in the following interview extract. (Student names are pseudonyms; 'I' is the interviewer.):

Extract 2 (Interview) - LA facilitating Engagement in the form of noticing and reflection:

I: What do you think about the grammar teaching?

Max: Seems very useful because, I think that just a simple grammar is not enough because if I want to read a newspaper, sometimes there is not just a simple sentence, will and write a lot of clause or compound, complex so I want to try out, to really take the maybe the subject and the object and which one is adjective which one is something, it's very complicated I think. But I think the grammar is the most important tool. More understand a lot of different piece of writing.

I: $\quad$ So would you like more, or do you think it's enough as it is?

Max: For me, I want more. In the writing, I can't just write a subject verb object and nothing else.

Max was acutely aware that he did not have the grammar needed to express the meanings he wanted. He noticed the complexity in the input which he had chosen as his target model, i.e. newspaper text. The impression is that his declarative grammar knowledge has facilitated Engagement in the form of noticing and reflection. The frustration at not having sufficient resources could be either discouraging or motivating. In Max's case, the impression was that this affective dimension intensified his cognitive Engagement with English.

When Max was asked if he wanted to have his mistakes corrected by the teacher, he indicated that corrections helped him notice:

Extract 3 (Interview) - Correction facilitating cognitive Engagement:

Max: I think it is very important because if something written is wrong then tutor correct for me, then I will notice 'oh this is wrong', so next time I will notice and I think I will guess and improve $\{\ldots\}$ about this.

\section{Affective Engagement}

In the analysis above, it was said that affective Engagement could be operationalized as degree of willingness, purposefulness and autonomy. The good humoured mood in the lesson - partly due to the teacher's approach, described above - contributed to the impression of willingness. Sporadically, there was low key laughter in the class. A particular episode stands out. In the extract below, the students are doing a listening comprehension exercise which involves matching pictures and questions with what they hear. The teaching points are comparative adjectives and use of 'all' and 'both'. The driver of the learners' Engagement is probably enjoyment of the competitive task. 
Extract 4 (Observation) - Affective Engagement/ willingness:

Tape: T says what [the tape] contains. (One conversation around each picture; SS pick out the question on the work sheet.)

SS appear to enjoy their 'successes'. There is quiet laughter and silent victory signs.

The students appeared to enter into the spirit of the task, making it a game. They were engaging willingly and deriving some pleasure from their achievements. The competitive element (perhaps not intended by the teacher) seemed to contribute to both affective and cognitive Engagement.

Along with the teacher's approach and the task design, the topic and type of text may have an effect on learners' willingness to Engage. In the sample interview, Max (below) appeared particularly keen to read and listen to factual texts such as newspapers and news reports. The learner worked purposefully on expanding his vocabulary. The driver seems to have been the intrinsic interest of topics and texts used in the classroom (and also available outside).

Extract 5 (Interview) - Affective/ Purposeful Engagement:

I: And is that what you enjoy most, learning to read and write or?

Max: Yes, to read what happened in this world. Because from just a couple of weeks ago we study a lot class this afternoon - it's about Britain and the world. It is very interesting. It encouraged me to, more hardworking to study English to try understand more and build up more vocabulary.

I: $\quad$ So do you like learning about the country?

Max: Yes.

I: The history and so on? You enjoy that.

Max: Yes.

The intrinsic interest of the material used in class spurred Max on to engage, particularly with the vocabulary.

The other student interviewee, Jenny, seemed to have a positive orientation towards the target language and what it represented. The following utterance follows immediately after the previous one. The driver here seems to be Jenny's self-perception.

Extract 6 (Interview) - Affective Engagement/Willingness:

Jenny: I proud when I can speak English.

Learning the language is clearly more to this student than a practical necessity.

Nevertheless, meeting objective needs and feeling motivated and satisfied go hand in hand. To a question about what they thought of the course content, the same student replied:

Extract 7 (Interview) - Affective/ Purposeful Engagement:

Jenny: Content? Could you explain please?

I: What they teach you. The things they teach you here, do you think that is what you need? Or what you want? Or do you need something else?

Jenny: You thought about the teacher teaching or me?

I: $\quad$ Yes, the school. What they have decided to teach you.

Jenny: Oh yes. I need here teaching speaking, some class for reading and writing, I think it's good. Because especially [name] $\{\ldots\}$ bring some thing - object for class and 
talking about that - operation, for hospital, for surgery, for telephone. This is, for me it is really interesting. I enjoy about that. Understand what's $\{\ldots\}$ or what is because sometimes I don't understand the telephone. It is very quickly to me $\{\ldots\}$ but when she bring for us, and after that understand better. I can speak with somebody and $\{\ldots\}$

The immediate relevance of the language being taught provided Jenny with a purpose for Engaging with it. Though other types of data would be needed to know the depth of the Engagement process, the extract shows that the student's own difficulties with telephone conversations made her keen to participate in classroom activities on this topic, which for her were obviously purposeful.

The sense of relevance and purpose made the two students Engage with the language not only in the classroom, but also independently at home:

Extract 8 (Interview) - Affective Engagement/ Autonomy:

I: $\quad$ So, you like the worksheets? To take home.

Jenny: Yes, yes, I can do it.

Max: Excuse me. Another, is not an activity, it's very useful is role-play.

I: Role play is useful? Yeah. Do you remember something you like especially? Can you give examples?

Jenny: Something like that? Example? About listening, with the tape. Before I couldn't understand nothing. But it's better. Very better. Because all the time teacher try for me, and I try at home, TV and radio. It's better than before, very better.

I: $\quad$ You are improving all the time.

Jenny: Very important.

For most ESOL students, the English language is key to a more secure and possibly more fulfilling future and so it is not surprising to find that some are highly selfmotivated and try to further their learning in a number of ways. It was often evident in both the interview and observation that Engagement was the learner's choice. Max even took the opportunity to follow additional courses:

Extract 9 (Interview) - Affective Engagement/ Autonomy:

I: $\quad$...What do you think - how much do you learn from your teacher, your classmates or by yourself?

Max: I think the half from the teacher, after, for example, if I've got time I back to home, I will do some revision from the tutor then try to find out more, encourage more to read, so maybe it is half by myself. But the tutor always give the opinion, like if I watch TV, subtitle only, I try to find maybe just a few vocabulary I can't understand, I look up my dictionary, and next time I will remember, then I know how to use it.

Max: ... And last Thursday I did how to improve communication skills, and this Thursday and Friday I want to try time management. Try to improve my English then maybe in the future I am going to the \{name\} College doing the EFF, EFL course. 


\section{Social Engagement}

In the previous analysis (tables 2 and 3 above), social Engagement was essentially linked to interaction and to learners' initiation and maintenance (or not) of it. Some of the extracts already discussed in terms of affective Engagement could also be analyzed from the social point of view. Below, I will however examine evidence of social Engagement in other parts of the interview data.

Key questions are firstly with whom the language learners/users need, want and are likely to interact and in what contexts. The students in the sample interview mentioned interaction in medical and shopping contexts; and with neighbours; job interviews; reading government documents, including solicitors' letters; and (as above) understanding people on the telephone.

Max cared particularly about the quality of his interaction outside the classroom and was aware of the importance of appropriate language.

Extract 10 (Interview) - Social Engagement - Maintaining interaction:

Max: Yes, definitely. Because sometimes English is very is very difficult for me, because it is, like speaking a formal and an informal, I should and I must understand which way is formal and which way is informal and which which place I can use these, and....

Not mastering colloquial varieties could make social interaction difficult for example in the work place or with neighbours. Another challenge mentioned was the natural speed of delivery which can make understanding difficult (Flowerdew and Miller, 1996; Graham, 2006), particularly in telephone conversations. There are many situations outside the classroom where there is a lack of thinking time. In the job interview, there is added pressure on the interviewee because of the power held by the interviewer.

In contrast, features of classroom interaction with potential to encourage and facilitate Engagement are the availability of thinking time, and the more egalitarian relationships between interlocutors (cf. Batstone, 2002). Individual learner variables nevertheless intervene. Max is keen to use peer interaction as a means of learning.

Extract 11 (Interview) - Social Engagement/ Readiness to interact:

I: $\quad$... What do you think of working in pairs and groups in the class?

Max: It's a good way to communicate. First you can get a communication with another classmate, and you can not sure, just express maybe after then you get something, like you can use each other, try to find out from the talking.

Jenny: Practice for talking and mainly practice for talking, practice for listening, accents, $\{\ldots\}$ very difficult. $\{.$.$\} English people, another \{\ldots\}$, young people, something is different, yeah $\{.$.$\} is happy to \{. .$.$\} the accent.$

'You can use each other, try to find out from the talking' encapsulates the notion of 'languaging' (Swain, 2006), a social manifestation of Engagement which Max finds helpful.

Jenny is less able to Engage in the framework of peer interaction, apparently because of differences in language proficiency (a power differential) and prefers the teacher's expert scaffolding. 
Extract 12 (Interview) - Social Engagement/ Readiness to interact:

I: $\quad$ Ok. So you think that pair and group work help you with this? Would you like to do more group and pair work or less, or what do you think?

Jenny: In the middle, a little bit $\{\ldots\}$ the teacher told is better, but yes this one practice is better, not too bad. Not a long time, because together I haven't a lot talking, just a little talk is finished. Me, I don't understand lots of, just a little talking. But with teacher help me I can speak longer.

As the two extracts show, Max is the more proficient of the pair of interviewees. He appreciates the opportunity to try things out with peers. For Jenny, both speaking and understanding in a group of more proficient students are very demanding. She needs the teacher to scaffold her. Despite the more accommodating nature of a classroom (as compared to external settings), it can apparently not be taken for granted that peer interaction will favour Engagement - in particular in mixed ability groups.

It was clear that the students' desire to be able to interact with a range of people in a variety of situations was not just for practical expediency. Max (below) wished to be regarded as a good neighbour. He sees himself acting as member of a community where TL is a vehicle and is aware of the effect misunderstandings might have on his relationships with neighbours and cares about the quality of interaction.

Extract 13 (Interview) - Social Engagement/ Maintaining interaction:

Max: Because for me I think by living in this country for ever I should understand language $\{\ldots\}$ I should use the language to communicate with the foreign people and I should understand a lot of piece of writing like government or official $\{\ldots\}$ like recycling or something. I live in the area - I didn't until now think my neighbours will say "this is foreigner, not good".

Max is anxious not to create a negative impression among his neighbours, for example by not being able to understand the rules for recycling household rubbish. Reading comprehension thus becomes especially important, but communicating with 'the foreign people' is also important ('foreign' here probably means in relation to him).

The language proficiency of adult ESOL students has an impact not only on the individual, but also on their families. Obvious needs are for example to find and keep jobs, but Jenny (below) had a less obvious need. She was concerned that she did not know English well enough to be able to help her son, probably with school work. In the extract below, Jenny presents herself as part of a family. She has a need to Engage (with English) in interaction with her child; this is thus interaction for teaching rather than learning. (On an affective level, it seems to also provide a purpose for Jenny's Engagement in the classroom.)

Extract 14 (Interview) - Social Engagement/ Readiness to interact:

Jenny: Grammar until now it's ok. I think I need a little better understand. Not just for because I have child, sometimes I need help my child. If I understand a lot, I can help my child with the $\{\ldots\}$. But at the moment, I think for can speak is learn, teach to us as well is ok. But I need, I think, I need understand more than because sometimes I am in charge for my child because $\{. .$.$\} difficult sometimes for my$ child very difficult and he needs...

I: And, do they teach you grammar sometimes?

Jenny: With my son?

I: No, here? The teachers? 
Jenny: Yes. But for me it's enough, I think. But I think I need much more about sometimes I can help my child.

Jenny may be trying to say that while the grammar she gets in class is sufficient to develop her own proficiency, she needs more declarative knowledge about English grammar in order to help her son. This is quite possibly a strong driver of her Engagement with grammar learning activities in class. Further on in the interview, Jenny also suggested that if she had had more than one child at school, this would have given her opportunity to practice English at home, her assumption being that the children would naturally prefer to speak English to each other. Hence, the presence of school age children in the immediate or extended family might encourage and facilitate Engagement with the language by older family members both in a classroom setting and at home.

The sample data were not designed to address the effect differences in gender, language, cultural and educational background might have on Engagement with Language in ESOL classrooms. A related issue is the link between identity and Engagement. Richards (2006, p.63 discussing classroom conversation data from Willis 1992) provides a striking example of how a teacher dismisses and effectively stops a learner's attempt to introduce a facet of their identity which is clearly essential to the learner. It could be useful to understand better what effect such incidents might have on the learner's Engagement.

\section{Facilitating or Impeding Engagement}

Returning to the quote at the start of the paper, I have claimed that LA researchers and practitioners are concerned with "LA as it encourages, facilitates, discourages or hinders particular types of engagement with language" (...: 302). Table 4 represents a first attempt to identify factors which do so. The qualities which would be affected have been repeated first (from table 2) for convenience. Factors which might influence presence or degree of Engagement positively are called 'drivers', and the negative factors, 'spanners'.

It is clear in Table 4 that cognitive, social and affective factors encroach on each other; cognitive Engagement can arguably be affected by emotional state, for example. Similar overlaps can be detected in regard to affective or social Engagement. For example, social interactive processes can be affected by perceived power differentials, which are also likely to influence affective factors such as trust. But for the purpose of analysis it seems useful to separate drivers and spanners of the three types of Engagement outcomes. 
Table 4 Engagement Drivers and Spanners

\begin{tabular}{|c|c|c|c|}
\hline & Cognitive & Affective & Social \\
\hline $\begin{array}{l}\text { Key } \\
\text { Characteristics }\end{array}$ & $\begin{array}{l}\text { State: Heightened } \\
\text { alertness; focused } \\
\text { attention } \\
\text { Process: Focused } \\
\text { reflection and problem } \\
\text { solving }\end{array}$ & $\begin{array}{l}\text { State: Positive orientation } \\
\text { towards the language, the } \\
\text { interlocutor, and/or what } \\
\text { they represent } \\
\text { Process: Willingness to } \\
\text { interact with the language } \\
\text { and/or interlocutor is } \\
\text { maintained/heightened }\end{array}$ & $\begin{array}{l}\text { State: Behavioural } \\
\text { readiness to interact } \\
\text { Process: Initiating and } \\
\text { responding positively to } \\
\text { interaction. }\end{array}$ \\
\hline $\begin{array}{l}\text { Drivers and } \\
\text { Spanners }\end{array}$ & $\begin{array}{l}\text { Energy levels (time of } \\
\text { day, state of health, low } \\
\text { adrenaline etc.) } \\
\text { Immediate } \\
\text { surroundings (noise, } \\
\text { lighting, temperature, } \\
\text { movement, colours); } \\
\text { Emotional state (stress, } \\
\text { worries; serenity) } \\
\text { Training (educational } \\
\text { background; culture of } \\
\text { learning prior } \\
\text { knowledge) } \\
\text { Task/activity design } \\
\text { (task demands within } \\
\text { ZPD, match with } \\
\text { learning style) } \\
\text { Teaching approach; } \\
\text { Teacher behaviour }\end{array}$ & $\begin{array}{l}\text { Personality type } \\
\text { (extrovert/introvert); } \\
\text { L self- perception (of own } \\
\text { knowledge and ability; self- } \\
\text { confidence; ); } \\
\text { Trust (how well do Ls } \\
\text { know/like each other?); } \\
\text { Topic (interesting, } \\
\text { offensive, relevant } \\
\text { topic/content) } \\
\text { Clarity of procedure and } \\
\text { purpose (how and why } \\
\text { should the task/activity be } \\
\text { done?); } \\
\text { Intrinsically motivating } \\
\text { quality of task/activity (e.g. } \\
\text { Relevance of purpose; right } \\
\text { level of intellectual } \\
\text { challenge; expected } \\
\text { success; competitive } \\
\text { element; opportunity to } \\
\text { engage in identity } \\
\text { construction) }\end{array}$ & $\begin{array}{l}\text { Power differentials } \\
\text { (equal/different status; } \\
\text { gate keeper -dependant; } \\
\text { equal/different language } \\
\text { proficiency; language } \\
\text { [variety] status) } \\
\text { Gender } \\
\text { (same/different } \\
\text { socialization; cultural/ } \\
\text { religious restrictions) } \\
\text { Social/Cultural belonging } \\
\text { (shared/different values, } \\
\text { schemata) } \\
\text { Social Networks } \\
\text { Family; friends; } \\
\text { colleagues; neighbours }\end{array}$ \\
\hline
\end{tabular}

\section{Conclusion}

This paper was prompted by the perception that for researchers and teachers (including postgraduate students), Engagement was a central notion. I have tried to show how Engagement can be defined and operationalized, and how it relates to LA: I have argued that LA can be simultaneously a result of and a resource for Engagement. The analysis attempts to provide a principled way of establishing, measuring and interpreting the presence/absence, degree and nature of Engagement. To the extent that this has succeeded, it should help make Engagement researchable. The discussion of the sample data shows, in my view, some of its potential to provide rich descriptions and analyses of complex environments such as the language classroom.

Engagement is clearly related to, but different from a number of other notions in the research literature. As defined here, it attempts to address what is, or is not, going on in the learning process. Other constructs, such as motivation (Gardner, 1985; Dörnyei, 2003) and investment (Norton, 1995) seem to deal more with the question 'why', which has only very briefly been addressed in the section on 'drivers' and 'spanners'. Other notions, such as agency (Ahern, 2001; Swain, 2006), and autonomy (Holec, 1981; Little, 
2007), it has been claimed, are incorporated in Engagement. 'Languaging' (Swain, 2006), finally, was said to be one observable manifestation of Engagement. It is up to the reader to decide whether this makes Engagement too all-encompassing to be useful, or if it may be a useful construct precisely because it brings together, in a principled way, a variety of aspects of a highly complex environment (notably the language classroom, e.g. Larsen-Freeman, 1997).

Several research avenues are possible. Systematic testing of sub-components of the Engagement construct could be as valuable as holistic research incorporating cognitive, affective and social aspects of Engagement. Questions which might be investigated within an Engagement framework include under what conditions it produces useful LA outcomes. For example, memorized grammar rules (a kind of LA) may be of limited use to the learner. Could this be to do partly with the kinds of Engagement typically required for memorization? What qualities, or combinations of qualities, should learners' Engagement have in order to produce learning? ${ }^{3}$ Research on different cognitive, affective and social aspects of Engagement might eventually be synthesized. Following Ellis's (2004) methodology (Figure 1 above) it is hoped that for any researcher wishing to conduct research on Engagement, the model presented above might help inform the choice of research design and measurement instruments, as well as the approach to data analysis, and that it will also stimulate a critical debate on related issues.

\section{Notes}

1. I am indebted to many of my doctoral students who have discussed this with me and helped me get to this stage of analysis. My initial set of features was somewhat modified on the basis of their input.

The The research objective was thus to match the aspirations of the NAECC in regard to the teaching of grammar against actual classroom practice and dynamics.

2. data was collected for, and discussed in, ... (2005) and is used here with the kind permission of my co-researcher.

3. Batstone (2002) conducts a discussion around a similar question but does not interrogate the engagement construct as such.

\section{References}

Ahearn, L. M. (2001). Language and agency. Annual Review of Anthropology 30, 109-137.

Armstrong, K. and Svalberg, A. M-L. (2005). Implementing the Adult ESOL Core Curriculum; subversion and compliance. Paper at Interrogating Third Spaces Conference (ITS 2005) University of Leicester.

Barnes, D. (1976).From Communication to Curriculum. Harmondsworth: Penguin.

Batstone, R. (2002). Contexts of engagement: a discourse perspective on 'intake' and 'pushed output'. System 30(1), 1-14.

Borg, S. (2007). Research engagement in English language teaching. Teaching and Teacher Education 23(5) 731-747.

Dörnyei, Z. (2003). Attitudes, orientations, and motivations in language learning : advances in theory, research and applications. Blackwell.

Dörnyei, Z. (2006) Motivation, language attitudes and globalisation : a Hungarian perspective. Clevedon: Multilingual Matters

Ellis, R. (2004). The definition and measurement of L2 explicit knowledge. Language Learning 54 (2), 227-275.

Flowerdew, J. and Miller, L. (1996) Lectures in a second language: Notes towards a cultural grammar. English for Specific Purposes 15(2), 121-140.

Gardner, R. C. (1985). Social psychology and second language learning : the role of attitudes and motivation. Edward Arnold.

Graham, S. (2006) Listening comprehension: The learners' perspective. System $34(2), 165-182$ 
Holec, H. (1981). Autonomy and foreign language learning. Oxford: Pergamon. Strasbourg: Council of Europe.

Hyland, F. (2003). Focusing on form: student engagement with teacher feedback. System 31(2), 217-230.

Kuiken, F. and Vedder, I. (2002) The effect of interaction in acquiring the grammar of a second language. International Journal of Educational Research 37, 343-358.

Larsen-Freeman, D. (1997). Chaos/Complexity Science and Second Language Acquisition. Applied Linguistics 18(2), 141-165.

Leow, R. P. (1997). Attention, awareness, and foreign language behaviour. Language Learning 47(3), 467505.

Little, D. (2007). Language learner autonomy: Some fundamental considerations revisited. Innovation in Language Learning and Teaching, 1 (1), 14-29.

Norton Peirce, B. (1995). Social Identity, Investment, and Language Learning. TESOL Quarterly 29(1), 931.

Pavicic Takac, V. (2008) Vocabulary Learning Strategies and Foreign Language Acquisition. Clevedon: Multilingual Matters, 2008

Qi, D. S., and Lapkin, S. (2001) Exploring the role of noticing in a three-stage second language writing task. Journal of Second Language Writing 10 (4), 277-303.

Richards, K. (2006). 'Being the Teacher': Identity and Classroom Conversation. Applied Linguistics 27(1), 51-77

Singleton, D. and Aronin, L. (2007). Multiple language learning in the light of the theory of affordances. Innovation in Language Learning and Teaching, 1(1), 83-96.

Storch, N. (2008). Metatalk in a pair work activity: Level of engagement and implications for language development. Language Awareness, 17(2), 95-114.

Svalberg, A. M-L. (2007) Language Awareness and Language Learning. Language Teaching 40(4), 287 308

Swain, M. (2000) The output hypothesis and beyond: Mediating acquisition through collaborative dialogue. In J. Lantolf (ed.), Sociocultural theory and second language learning. (pp.97-114). Oxford: Oxford University Press.

Swain, M. (2006, April) Languaging, agency and collaboration in second language learning. Plenary address at BAAL Language Learning and Teaching SIG Conference: Language Use, Language Processing and Language Learning, Southampton University.

Van Lier, L.. (2007) Action-based teaching, autonomy and identity. Innovation in Language Learning and Teaching, 1(1), 46-65.

Willis, J. (1992) Inner and outer: Spoken discourse in the language classroom. In M. Coulthard (ed.) Advances in spoken discourse. (pp.162-82). London: Routledge. 